\title{
Amyloid myopathy and myeloma: response to treatment
}

\author{
R.A. Sheehan-Dare and A.V. Simmons \\ St James's University Hospital, Beckett Street, Leeds LS9 7TF, UK.
}

\begin{abstract}
Summary: A 57 year old female presented with an amyloid myopathy in association with lambda light chain myeloma. Treatment with melphalan and prednisolone resulted in remission of both myeloma and myopathy.
\end{abstract}

\section{Introduction}

Both primary and secondary amyloidosis are uncommon disorders. Monoclonal immunoproteins, particularly light-chains, can be demonstrated in a majority of patients with primary amyloidosis. ${ }^{1}$ Frank myeloma is present less frequently. The incidence of amyloidosis in patients with myeloma is $6-15 \%{ }^{2}$ The prognosis of primary amyloidosis is poor (median survival $4.9-14.7$ months from diagnosis). ${ }^{2}$ It is worse when myeloma is present (median survival 4-5 months from diagnosis). ${ }^{2}$ Most patients who present as 'primary' amyloidosis die from its complications. Cytotoxic chemotherapy has been used in the treatment of primary amyloidosis, whether or not a plasma cell dyscrasia has been demonstrated. Success has been variable.

\section{Case report}

A 57 year old woman presented with a 6-month history of progressive muscular weakness, lethargy and weight loss. Two months previously a diagnosis of right carpal tunnel syndrome had been made. On examination there was marked muscle weakness and wasting in a predominantly proximal distribution. Tendon reflexes were diminished. Fasciculation was not seen. There was no sensory deficit. Moderate ankle oedema was present.

Investigations included haemoglobin $14.3 \mathrm{~g} / \mathrm{dl}$, white cell count $13.3 \times 10^{9} / 1$, erythrocyte sedimentation rate $2 \mathrm{~mm} /$ hour, total serum protein $46 \mathrm{~g} / \mathrm{l}$, serum albumin $28 \mathrm{~g} / \mathrm{l}$ and adjusted serum calcium 2.24 $\mathrm{mmol} / \mathrm{l}$. There was considerable proteinuria. Serum immunoglobulin levels were depressed, serum IgG $5.1 \mathrm{~g} / \mathrm{l}, \mathrm{IgA} 0.4 \mathrm{~g} / 1$ and IgM $0.1 \mathrm{~g} / 1$. Urine electro-

Correspondence: $\quad$ R.A. Sheehan-Dare, M.B., Ch.B., M.R.C.P.

Accepted: 12 August 1986 phoresis revealed lambda light chains. The bone marrow was examined, $48 \%$ of cells present were plasma cells and indicated a diagnosis of myeloma. Electromyography (EMG) showed a uniform myopathic pattern with brief duration polyphasic motor unit potentials of low voltage. There was right median nerve conduction delay but no evidence of polyneuropathy. A quadriceps femoris muscle biopsy showed gross atrophy (particularly of type II cells), focal necrosis and regeneration. Amyloid was present in much of the endomysium, in blood vessel walls and connective tissue generally. The motor innervation showed no evidence of neuropathy. A diagnosis of myeloma with amyloid myopathy and nephrotic syndrome was made.

The patient was treated with 7 day courses of melphalan $10 \mathrm{mg} /$ day and prednisolone $40 \mathrm{mg} /$ day at 4 weekly intervals. After 8 months of treatment she was well and there had been marked improvement in the power of all muscle groups. No light-chains were now detectable in the urine. Repeat bone marrow examination showed plasma cells to be less than $2 \%$ of the cells present. Twenty-four hour urinary protein excretion had been reduced to $0.04 \mathrm{~g} / 24$ hours. Repeat electromyography showed a striking reduction in the myopathic disturbance with restoration of many more motor potentials of normal duration and voltage.

Five months later right carpal tunnel decompression and repeat quadriceps femoris muscle biopsy were performed. Histology showed some muscle atrophy with nuclear agglomeration but no necrosis or regeneration. Amyloid was present still in the vessel walls and interstitial tissue, but was less in amount than previously. No amyloid was found in the flexor retinaculum.

The patient remained stable for 4 years. She then relapsed with recurrence of her myeloma. She developed macroglossia, progressive congestive heart failure and died. Permission for post-mortem examination was refused. 


\section{Discussion}

There have been few documented remissions of secondary amyloidosis. Occasional patients have improved with treatment of the underlying disorder, some spontaneously. Histological evidence for regression of amyloid has been presented only rarely. ${ }^{3}$ Clinical remission in primary amyloidosis is equally unusual. Some case reports have cited improvement of nephrotic syndrome after treatment with melphalan and prednisolone with or without other cytotoxic agents or penicillamine. ${ }^{4,5,6}$ Few provide histological evidence for regression of amyloid, ${ }^{7}$ some reporting progression of deposition despite clinical im-

\section{References}

1. Kyle, R.A. \& Greipp, P.R. Amyloidosis (AL): clinical and laboratory features in 229 cases. Mayo Clin Proc 1983, 58: 665-683.

2. Glenner, G.G. Amyloid deposits and amyloidosis. $N$ Engl J Med 1980, 302: 1333-1334.

3. Dikman, S.H., Kahn, T., Gribetz, D. \& Churg, J. Resolution of renal amyloidosis. Am J Med 1977, 63: 430-433.

4. Cohen, H.J., Lissen, L.S., Hallal, J. \& Burkholder, P. Resolution of primary amyloidosis during chemotherapy. Studies in a patient with nephrotic syndrome. Ann Intern Med 1975, 82: 466-473.

5. Jones, N.F., Hilton, P.J., Tighe, J.R. \& Hobbs, J.R. Treatment of primary renal amyloidosis with melphalan. Lancet 1972, ii: 616-619. provement. $^{8}$ A search of previous publications $\frac{2}{z}$ provides only one description of a case of amyloidosis $\frac{\mathbb{Q}}{8}$ with myeloma which regressed with chemotherapy. ${ }^{9}$

Patchy distribution of amyloid can occur and this may have an effect on histological comparisons of biopsy specimens. Notwithstanding this, we believe that our patient showed good clinical and histological evidence of regression of amyloid deposits. The clinical improvement was maintained for 4 years.

Primary amyloidosis is an uncommon disorder with क a poor prognosis, particularly if myeloma is present. This case report demonstrates that occasional patients respond to melphalan and prednisolone. An attempt at treatment with these drugs is therefore justified.

6. Schwartz, R.S., Cohen, J.R., \& Schrier, S.L. Therapy of primary amyloidosis with melphalan and prednisolone. Arch Intern Med 1979, 139: 1144-1147.

7. Buxbaum, J.N., Hurley, M.E., Chuba, J. \& Spiro, T. 음 Amyloidosis of the AL type: clinical, morphological and biochemical aspects of the response to therapy with 7 alkylating agents and prednisolone. Am J Med 1979, 67: 867-878.

8. Kyle, R.A., Wagoner, R.D. \& Holley, K.E. Primary systemic amyloidosis: resolution of the nephrotic syndronge with melphalan and prednisolone. Arch Intern Med 198 142: 1445-1447.

9. Mehta, A.D. Regression of amyloidosis in multip myeloma. Br J Clin Pract 1978, 32: 358-359. 